\title{
Genotypic and Phenotypic Diversity within Streptococcus anginosus
}

\author{
R. A. WHILEY, ${ }^{1 *}$ L. M. C. HALL, ${ }^{2}$ J. M. HARDIE, ${ }^{1}$ AND D. BEIGHTON ${ }^{3}$ \\ Department of Oral Microbiology, ${ }^{1}$ and Department of Medical Microbiology, ${ }^{2}$ St. Bartholomew's and The Royal \\ London School of Medicine and Dentistry, London E1 2AD, and Joint Microbiological Research Unit, \\ King's College School of Medicine and Dentistry, London SE5 9RW, United Kingdom
}

\begin{abstract}
Streptococcus anginosus is one of the three species currently included in the "anginosus group" of oral or viridans streptococci. In this study 21 strains of $S$. anginosus were examined in order to determine whether this species, as currently defined, is sufficiently heterogeneous to warrant further subdivision. Phenotypic strain characterization was carried out by performing biochemical tests with a commercial system (Rapid ID32 STREP kit; bioMerieux), by performing tests to determine hyaluronidase production, hemolysis on blood agar, and gliding motility on chocolate agar, by determining Lancefield groups, and by comparing whole-cell polypeptide patterns obtained by sodium dodecyl sulfate-polyacrylamide gel electrophoresis (SDS-PAGE). Variations in genotype were determined by studying 16S-23S rRNA intergenic spacer size polymorphisms by PCR amplification, by ribotyping, and by performing DNA-DNA base pairing studies. $S$. anginosus was found to be heterogeneous at both the species and intraspecies (subspecies) levels. Beta-hemolytic Lancefield group C strains that did not produce hyaluronidase formed a DNA homology group that was separate from the majority of the $S$. anginosus strains; the members of this group produced a 380-bp intergenic spacer PCR product, exhibited distinct ribotypes, produced an atypical SDS-PAGE pattern, and represented a previously undescribed species in the anginosus group. Two other strains (ATCC 9895 and 1007-77) remained ungrouped as determined by DNA-DNA hybridization and thus represented additional centers of variation at the species level. Hyaluronidase-producing, beta-hemolytic, Lancefield group $\mathrm{C}$ strains produced the same atypical SDSPAGE pattern as beta-hemolytic Lancefield group $\mathrm{C}$ strains that did not produce hyaluronidase but differed from the latter organisms by producing a 600-bp intergenic spacer PCR product. In addition, both DNA homology data and ribotyping data suggested that these strains comprise a subspecies of $S$. anginosus. With the notable exception of the beta-hemolytic Lancefield group $\mathrm{C}$ strains that did not produce hyaluronidase, strains ATCC 9895 and 1007-77, and the beta-hemolytic Lancefield group C hyaluronidase-producing strains mentioned above, the strains studied formed a closely related group within which some additional genotypic and phenotypic heterogeneity was observed. The latter group included both strains that fermented mannitol and strains that did not ferment mannitol, as well as strains that exhibited so-called gliding motility. Although no clear-cut division of these organisms was possible, our results indicate that strain NCTC 10713 may not be the most suitable type strain for $S$. anginosus. We concluded that $S$. anginosus strains exhibit sufficient heterogeneity to warrant division at both the species and subspecies levels, although insufficient numbers of strains belonging to the putative new taxa have been characterized to allow formal taxonomic proposals to be made.
\end{abstract}

The genus Streptococcus comprises six species groups recognized on the basis of 16S rRNA gene sequence data; these groups are designated the "pyogenic," "anginosus," "mitis," "salivarius," "bovis," and "mutans" groups $(2,16)$. The members of the anginosus group, which is also referred to as the "Streptococcus milleri group" (SMG), are isolated from oral cavities and from gastrointestinal and genitourinary tracts and are associated with purulent infections at a wide range of anatomical sites in humans $(14,20,26)$. Until recently, the taxonomic status and nomenclature of these streptococci were the subject of considerable debate; some authors included all of the strains in a single DNA homology group or species $(6,9$, $11,24)$, while other authors described more than one DNA homology group $(17,18,29)$ or assigned isolates to one of several species defined on the basis of biochemical test data (10). The conflicting DNA homology data reported previously have been attributed to differences in the DNA reassociation methods cmployed and to differences in the strains used $(6,18$, 29).

Recent studies have resulted in the description of the fol-

* Corresponding author. Phone: 0171377 7000, ext. 3219. Fax: 0171 247 0657. 1-mail: R. A. Whiley@mds.qmw.ac.uk. lowing three species in the anginosus group: Streptococcus anginosus, Streptococcus constellatus, and Streptococcus intermedius (25). Isolates can be assigned to these species by using a limited number of biochemical tests (28). However, previously published evidence indicates that there is a considerable level of intraspecific diversity within $S$, anginosus as currently defined. $S$. anginosus strains obtained from the genitourinary tract are frequently members of a distinct biotype and are able to ferment mannitol and/or raffinose, in contrast to strains obtained from other sites $(1,26)$. S. anginosus strains with these biochemical characteristics have also been differentiated on the basis of cell membrane long-chain fatty acid composition and on the basis of pyrolysis mass spectrometry data (5, 32). During studies carried out in our laboratory, a relatively broad range of DNA homology levels (51 to 100\%) was observed between the $S$. anginosus strains examined (29). Heterogeneity within $S$. anginosus has also been observed in rRNAbased studies, including studies to determine $16 \mathrm{~S}$ rRNA sequences (3), 16S-23S rRNA intergenic spacer size polymorphisms (27), and ribotypes (8). Bergman et al. (3) have also described strains, which were most closely related to $S$. anginosus as determined by $16 \mathrm{~S}$ rRNA gene sequence comparisons, that exhibited gliding motility on some chocolate agar 
media, although the taxonomic status of these strains was uncertain.

In the present study strains representing the main phenotypic variants described above were examined and characterized by using both phenotypic and genotypic approaches in order to determine the intraspecific diversity of $S$. anginosus as the species is currently defined.

\section{MATERIALS AND METHODS}

Bacterial strains and growth conditions. We studied 18 strains of $S$. anginosus identified by using the biochemical scheme of Whiley et al. (28), 3 strains (69130, $\mathrm{MGH}$, and SJMC) that exhibit gliding motility on chocolate agar as reported by Bergman et al. (3), and the type strains of S. intermedius (NCDO 2227 [ = NCTC $11324=$ ATCC 27335]) and $S$. constellatus $($ NCDO $2226[=$ NCTC $11325=$ ATCC 27823]). The $S$. anginosus reference strains used included the type strain, strain NCTC 10713 (= ATCC $33397=$ DSM 20563), and reference strain ATCC 9895 , both of which were isolated from throats. Mannitol-fermenting clinical strains KR455 (from urine), KR687 (from an axillary abscess), and 757 (from a Bartholin cyst), mannitol-fermenting motile strains 69130 (from urine) and SJMC (from urine), and motile strain MGH which did not ferment mannitol (from an unknown clinical source) were obtained from K. Ruoff, Massachusetts General Hospital, Boston. Mannitol-fermenting strains Q3799 (from higher vaginal swab [HVS]) and Q4039 (from HVS), together with beta-hemolytic Lancefield group C strains M5823 (from an abdominal mass) and I751s (from a throat), were obtained from T. Winstanley, Royal Hallamshire Hospital, Sheffield, United Kingdom. Mannitol-fermenting strains $138 \mathrm{ii}$ and 153ii (both from the rectal mucosa of colitis patients) were obtained from $M$. Hudson, PHLS Centre for Applied Microbiology and Research, Porton Down, United Kingdom. Strain G5:3 (from dental plaque) was obtained from B. Mejaré, University of Lund, Malmo, Sweden. Strain PC4890 (from dental plaque) was obtained from the Department of Oral Microbiology, St. Bartholomew's and The Royal London School of Medicine and Dentistry, London, United Kingdom. Beta-hemolytic Lancefield group C strain W558 (from an arm burn swab) was obtained from the Department of Medical Microbiology, Royal London Hospital Trust, London, United Kingdom. Beta-hemolytic Lancefield group C strain NMH3 (from a pelvic abscess) was obtained from M. W. D. Wren, formerly of North Middlesex Hospital, London, United Kingdom. Strain PHLS 430 (from an appendix) was obtained from P. Poole, Public Health Laboratory, Chester City Hospital, Chester, United Kingdom. Strain SL28 (from an appendix) was obtained from P. Handley, School of Biological Sciences, University of Manchester, Manchester, United Kingdom, and strain 1007-77 (from a wound) was obtained from R. Facklam, Centers for Disease Control and Prevention, Atlanta, Ga. All strains were stored at $-70^{\circ} \mathrm{C}$ on glass beads by using a commercial storage system (Technical Service Consultants, Ltd., Heywood, Lancashire, United Kingdom) and were routinely maintained on Columbia blood agar (Gibco BRL, Life Technologies, Paisley, Scotland, United Kingdom) containing $5 \%$ (vol/vol) defibrinated horse blood (TCS Microbiological Ltd., Buckingham, United Kingdom).

The bulk quantities of strains used to prepare DNA for DNA reassociation experiments and for ribotyping were grown in brain heart infusion broth (Oxoid, Unipath Ltd., Basingstoke, Hampshire, United Kingdom) containing $0.5 \%$ glu$\operatorname{cose}(5 \mathrm{~g} /$ liter $)$. Glycine $(10 \mu \mathrm{g} / \mathrm{ml})$ was added when the cultures reached the late logarithmic phase (as determined visually); then the cultures were incubated for an additional $1 \mathrm{~h}$, chilled in ice-water, and harvested by centrifugation. The DNA minipreparations used for PCR were obtained from $5-\mathrm{ml}$ cultures grown in the same broth for 4 to $5 \mathrm{~h}$; these cultures were not treated with glycine. All incubations were at $37^{\circ} \mathrm{C}$ in an anacrobic atmosphere containing $20 \% \mathrm{H}_{2}, 10 \%$ $\mathrm{CO}_{2}$, and $70 \% \mathrm{~N}_{2}$

Phenotypic tests. Strains were examined for all of the phenotypic characteristics described below. All strains were tested by using commercial identification strips (Rapid ID32 STREP; bioMerieux, Marcy l'Etoile, France). Hyaluronidase production was tested on agar plates containing $400 \mu \mathrm{g}$ of hyaluronic acid (sodium salt from human umbilical cord; Sigma Chemical Co., St. Louis, Mo.) per $\mathrm{ml}$ and $1 \%(\mathrm{wt} / \mathrm{vol}$ ) bovine serum albumin (fraction V; Sigma) by the plate method of Smith and Willet (22). Hemolysis was examined by using layered Columbia blood agar plates containing $5 \%(\mathrm{vol} / \mathrm{vol})$ defibrinated horse blood that were incubated anaerobically at $37^{\circ} \mathrm{C}$ for 24 and $48 \mathrm{~h}$. Lancefield serological group reactions were detected with a commercial kit (Oxoid Ltd.).

Motility. Strains were tested for so-called gliding motility on commercially produced chocolate agar plates (GC II with IsoVitalex; BBL, Becton Dickinson U.K. Ltd., Oxford, United Kingdom) that were incubated for up to $72 \mathrm{~h}$, as described previously (3).

Whole-cell protein patterns as determined by SDS-PAGE. Sodium dodecyl sulfate-polyacrylamide gel electrophoresis (SDS-PAGE) whole-cell protein patterns were obtained by using $10 \%$ acrylamide slab gels as described previously (29). The patterns were revealed by staining the gels with Coomassie brilliant blue R (Sigma).

PCR amplification of the 16S-23S rRNA intergenic spacer regions. Harvested cells grown in 5-ml broth cultures as described above were resuspended in $0.1 \mathrm{ml}$ of TE buffer ( $10 \mathrm{mM}$ Tris, $1 \mathrm{mM}$ EDTA; $\mathrm{pH} 8.0)$ and incubated at $37^{\circ} \mathrm{C}$ for $1 \mathrm{~h}$ with $20 \mu \mathrm{l}$ of a lysozyme solution $(50 \mathrm{mg} / \mathrm{ml}$ in TE buffer). GES solution ( $5 \mathrm{M}$ guanidium thiocyanate, $0.5 \mathrm{M}$ EDTA, $0.5 \%$ [wt/vol] $N$-lauroylsarcosine [sodium salt]; $\mathrm{pH} 8.0$ ) was added, and, after the preparation was vortexed briefly, lysis was monitored visually for approximately $5 \mathrm{~min}$. A $0.25-\mathrm{ml}$ portion of cold $7.5 \mathrm{M}$ ammonium acetate was added, and the mixture was placed on ice for $10 \mathrm{~min}$. The lysate was deproteinized by mixing it with $0.5 \mathrm{ml}$ of chloroform-isoamyl alcohol (24:1); this was followed by centrifugation at $13,000 \times g$ for $10 \mathrm{~min}$, and $0.7 \mathrm{ml}$ of the resulting supernatant was transferred to a clean tube. A $0.38-\mathrm{ml}$ portion of cold isopropanol was added, and following mixing by gentle inversion, centrifugation at $13,000 \times g$ was carried out for $2 \mathrm{~min}$. The resulting pellet was redissolved in approximately $200 \mu \mathrm{l}$ of TE buffer and reprecipitated with $0.5 \mathrm{ml}$ of cold ethanol. Finally, the pellet was dissolved in $100 \mu \mathrm{l}$ of distilled $\mathrm{H}_{2} \mathrm{O}$. A PCR was performed with GeneAmp PCR core reagents, including $2.5 \mathrm{mM} \mathrm{MgCl}$, and AmpliTaq polymerase (Perkin-Elmer Cetus). The primers used were primers $A$ (5'-GAAGTCGTAACAAGGTA(AG)CCGT-3') and B (5'-TGCCAAGGCAT CCACC $-3^{\prime}$ ) (corresponding to positions 1491 to 1512 [16S rRNA] and 23 to 38 [23S rRNA], respectively [Escherichia coli numbering]). The PCR conditions were as follows: $95^{\circ} \mathrm{C}$ for $1 \mathrm{~min}, 55^{\circ} \mathrm{C}$ for $1 \mathrm{~min}$, and $72^{\circ} \mathrm{C}$ for $1 \mathrm{~min}$ for 30 cycles in a OmniGene thermal cycler (Hybaid, Teddington, Middlesex, United Kingdom). The concentration of each primer was $1 \mu \mathrm{g} / \mathrm{ml}$. PCR amplification products were analyzed on $1.5 \%$ agarose gels.

Ribotyping. Ribotyping was carried out with five strains that did not ferment mannitol (strains G5:3, 1007-77, PHLS 430, SL28, and NCTC 10713 ${ }^{\mathrm{T}}$ ), mannitolfermenting strains Q3799, 153ii, 138ii, and 757, motile strains MGH (which did not ferment mannitol), 69130 (which fermented mannitol), and SJMC (which fermented mannitol), and beta-hemolytic Lancefield group $\mathrm{C}$ strains $1751 \mathrm{~s}$ M5823, NMH3, and W558. The type strains of $S$. constellatus (NCDO 2226) and $S$. intermedius (NCDO 2227) were also examined. DNA preparations were obtained from 20- to 50-ml broth cultures grown and harvested as described above DNA was prepared as described above for the PCR experiments by using scaled-up quantities of reagents. DNA (approximately $3 \mu \mathrm{g}$ ) was digested to completion with HindIII, and fragments were separated in $0.9 \%$ agarose gels in Tris-borate buffer. Following denaturation in $0.5 \mathrm{M} \mathrm{NaOH}-1.5 \mathrm{M} \mathrm{NaCl}$ and neutralization in $0.5 \mathrm{M}$ Tris-1.5 M NaCl-0.001 M EDTA (pH 7.2), DNA frag ments were transferred to Hybond-N membranes (Amersham International plc Buckinghamshire, United Kingdom) in a positive-pressure cell (Stratagene, Ltd. Cambridge, United Kingdom). The DNA was fixed by exposure to UV light, hybridized to a dUTP-digoxygenin-labelled probe containing $16 \mathrm{~S}, 23 \mathrm{~S}$, and $5 \mathrm{~S}$ rRNA genes from $E$. coli in plasmid pk3535 (4), and visualized with a nonradioactive alkaline phosphatase-linked anti-digoxigenin antibody detection system used as recommended by the manufacturer (Boehringer Mannheim UK Ltd., Sussex, United Kingdom).

DNA reassociation. DNA was prepared from approximately $3 \mathrm{~g}$ (wet weight) of cells by the method of Garvie (13). DNA purity was monitored by measuring absorbance at 260 and $280 \mathrm{~nm}$ and by agarose gel electrophoresis. Radioactive DNA was labelled with $\left[1^{\prime}, 2^{\prime}, 5-{ }^{3} \mathrm{H}\right] \mathrm{dCTP}$ (Amersham International plc) by nick translation by using a commercial kit as recommended by the manufacturer (Amersham International plc). Labelled DNAs were prepared from strains NCTC $10713^{\mathrm{T}}, 138 \mathrm{ii}, 69130$, W558, and $\mathrm{I} 751 \mathrm{~s}$. DNA reassociation experiments were performed in triplicate in $300 \mu \mathrm{l}$ of $0.42 \mathrm{M} \mathrm{NaCl}$ containing $30 \mu \mathrm{g}$ of sheared (sonicated), denatured unlabelled DNA and $0.02 \mu \mathrm{g}$ of sheared, denatured labelled DNA under optimum $\left(60^{\circ} \mathrm{C}\right)$ and stringent $\left(75^{\circ} \mathrm{C}\right)$ conditions by using the $\mathrm{S} 1$ nuclease method of Crosa et al. (7) modified as described by Shah et al. (21), as described previously (29).

\section{RESULTS}

Phenotypic characterization. The following tests were positive for all strains as determined with the Rapid ID32 STREP test kits (bioMerieux): production of $\beta$-D-glucosidase, alanylphenylalanyl-proline arylamidase, alkaline phosphatase, and arginine dihydrolase; acetoin (Voges-Proskauer) reaction; and production of acid from sucrose and maltose. The following tests were negative for all strains: production of $\beta$-glucuronidase, $\beta$-galactosidase (naphtholic substrate), pyrolidonyl arylamidase, $\beta-N$-acetylglucosaminidase, glycyl-tryptophan arylamidase, and urease; hydrolysis of hippurate; and production of acid from ribose, sorbitol, glycogen, melezitose, L-arabinose, D-arabitol, tagatose, and cyclodextrin. All strains were identified as $S$. anginosus in the Rapid ID32 STREP numerical profile index. In most cases the confidence level was $\geq 97.9 \%$; the only exceptions were beta-hemolytic Lancefield group C strains I751s, NMH3, and W558 (confidence level, 96.3\%) and strains PC4890 and 1007-77 (78.6\%). All variable biochemical characteristics are shown in Table 1. 
TABLE 1. Phenotypic characteristics of $S$. anginosus strains ${ }^{a}$

\begin{tabular}{|c|c|c|c|c|c|c|c|c|c|c|}
\hline \multirow{2}{*}{ Strain } & \multicolumn{2}{|c|}{ Production of: } & \multicolumn{6}{|c|}{ Production of acid from: } & \multicolumn{2}{|c|}{ Production of: } \\
\hline & $\beta G A R$ & $\alpha G A L$ & Mannitol & Lactose & Trehalose & Raffinose & Pullulan & Melibiose & MßDG & BMAN \\
\hline NCTC $10713^{\mathrm{T}}$ & - & - & - & + & + & + & + & - & + & - \\
\hline PHLS 430 & - & - & - & - & + & - & + & - & - & + \\
\hline PC4890 & - & - & - & + & + & - & - & - & - & - \\
\hline SL28 & - & - & - & - & + & - & + & - & + & - \\
\hline G5:3 & - & - & - & + & + & - & + & - & + & - \\
\hline KR455 & + & + & + & + & + & + & + & - & + & - \\
\hline KR687 & - & + & + & + & + & + & + & - & + & - \\
\hline Q4039 & - & + & + & + & + & + & + & - & + & - \\
\hline $138 \mathrm{ii}$ & - & - & + & + & + & + & + & - & + & - \\
\hline $153 \mathrm{ii}$ & - & - & + & + & + & + & + & - & + & - \\
\hline 757 & + & + & + & + & + & + & + & + & + & - \\
\hline Q3799 & + & - & + & + & + & + & + & - & + & - \\
\hline SJMC & - & - & + & - & + & - & + & - & + & - \\
\hline 69130 & - & + & + & + & + & + & + & - & + & - \\
\hline $\mathrm{MGH}$ & + & + & - & + & + & + & - & + & + & - \\
\hline NMH3 & + & - & - & + & + & - & + & - & + & - \\
\hline W558 & + & - & - & + & + & - & + & - & + & - \\
\hline I751s & + & - & - & + & + & - & + & - & + & - \\
\hline M5823 & + & - & - & + & - & - & + & - & + & - \\
\hline ATCC 9895 & - & - & - & + & + & - & + & - & + & - \\
\hline $1007-77$ & - & - & - & + & + & - & - & - & - & + \\
\hline
\end{tabular}

${ }^{a}$ Abbreviations: $\beta$ GAR, $\beta$-galactosidase; $\alpha \mathrm{GAL}, \alpha$-galactosidase; M $\beta D G$, methyl- $\beta$-D-glucopyranosidase; $\beta$ MAN, $\beta$-mannosidase.

The Lancefield group, hemolysis, and motility test results are shown in Table 2 .

SDS-PAGE of whole-cell proteins. $S$. anginosus strains produced very similar SDS-PAGE whole-cell protein band pat- terns with only minor interstrain differences (Fig. 1). The most obvious variation was observed with the four beta-hemolytic Lancefield group C strains (strains I751s, M5823, NMH3, and W558), which were characterized by the presence of a rela-

TABLE 2. Levels of DNA relatedness between S. anginosus strains

\begin{tabular}{|c|c|c|c|c|c|c|c|c|c|c|c|c|c|c|}
\hline \multirow[b]{2}{*}{ Source of unlabelled DNA } & \multicolumn{9}{|c|}{ Phenotype $^{a}$} & \multicolumn{5}{|c|}{$\%$ DNA relatedness to: } \\
\hline & $\mathrm{Mn}$ & $\mathrm{R}$ & M & 1 & Hyl & $\mathrm{L}$ & $\mathrm{H}$ & Mt & $\beta g$ & $\begin{array}{l}\text { NCTC } \\
10713^{T}\end{array}$ & $138 \mathrm{ii}$ & 69130 & W558 & I751s \\
\hline \multicolumn{15}{|l|}{ S. anginosus strains } \\
\hline NCTC $10713^{\mathrm{T}}$ & - & + & - & + & - & $\mathrm{G}$ & $\beta^{b}$ & - & - & $100(100)^{c}$ & $64(41)$ & $61(42)$ & $71(50)$ & 48 \\
\hline PHLS 430 & - & - & - & - & - & $\mathrm{F}$ & - & - & - & $73(54)$ & $84(55)$ & 55 & $62(36)$ & 45 \\
\hline PC4890 & - & - & - & + & - & $\mathrm{C}$ & - & - & - & $81(42)$ & 102 & $87(100)$ & 76 & 40 \\
\hline SL28 & - & - & - & - & - & $\mathrm{F}$ & - & - & - & $82(43)$ & $93(45)$ & 85 & 74 & $39(20)$ \\
\hline $\mathrm{G} 5: 3$ & - & - & - & + & - & $\mathrm{F}$ & - & - & - & $73(53)$ & $\mathrm{NT}^{d^{\prime}}$ & 51 & 62 & $43(48)$ \\
\hline KR455 & + & + & - & + & - & $\mathrm{N}^{e}$ & - & - & + & $70(75)$ & $102(120)$ & 114 & $68(64)$ & $43(35)$ \\
\hline KR687 & + & + & - & + & - & $\mathrm{F}$ & $\beta$ & - & - & $70(43)$ & NT & 106 & $71(73)$ & 50 \\
\hline Q4039 & + & + & - & + & - & $\mathrm{G}$ & - & - & - & $70(55)$ & $102(104)$ & $109(89)$ & $64(65)$ & $38(11)$ \\
\hline $138 \mathrm{ii}$ & + & + & - & + & - & $\mathrm{F}$ & - & - & - & $59(48)$ & $100(100)$ & 90 & $53(31)$ & 51 \\
\hline $153 \mathrm{ii}$ & + & + & - & + & - & $\mathrm{F}$ & - & - & - & $64(47)$ & $76(120)$ & 78 & 64 & 52 \\
\hline 757 & + & + & + & + & - & $\mathrm{F}$ & - & - & + & $61(47)$ & $86(107)$ & $91(120)$ & $57(60)$ & $39(42)$ \\
\hline Q3799 & + & + & - & + & - & $\mathrm{F}$ & - & - & + & $56(48)$ & $79(103)$ & 81 & $57(66)$ & $40(18)$ \\
\hline SJMC & + & - & - & - & - & $\mathrm{N}$ & - & + & - & $77(71)$ & $101(113)$ & 116 & 72 & 48 \\
\hline 69130 & + & + & - & + & - & $\mathrm{F}$ & - & + & - & $59(48)$ & $95(72)$ & $100(100)$ & $65(42)$ & 36 \\
\hline MGH & - & + & + & + & - & G & - & + & + & $55(46)$ & $80(109)$ & $79(80)$ & $60(37)$ & 36 \\
\hline NMH3 & - & - & - & + & + & $\mathrm{C}$ & $\beta$ & - & + & $69(53)$ & $67(54)$ & 59 & $87(87)$ & 55 \\
\hline W558 & - & - & - & + & + & $\mathrm{C}$ & $\beta$ & - & + & $62(46)$ & $52(38)$ & $52(22)$ & $100(100)$ & 51 \\
\hline I751s & - & - & - & + & - & $\mathrm{C}$ & $\beta$ & - & + & $56(33)$ & $61(35)$ & $50(9)$ & $55(16)$ & $100(100)$ \\
\hline M5823 & - & - & - & + & - & $\mathrm{C}$ & $\beta$ & - & + & $58(30)$ & $56(32)$ & 55 & $54(47)$ & $102(60)$ \\
\hline ATCC 9895 & - & - & - & + & - & $\mathrm{F}$ & - & - & - & $59(45)$ & 44 & $34(16)$ & 55 & 33 \\
\hline $1007-77$ & - & - & - & + & - & A & - & - & - & $66(38)$ & $53(35)$ & $58(20)$ & $60(29)$ & 34 \\
\hline S. intermedius NCDO $2227^{\mathrm{T}}$ & & & & & & & & & & $47(22)$ & $41(26)$ & 38 & 39 & 48 \\
\hline S. constellatus $\mathrm{NCDO} 2226^{\mathrm{T}}$ & & & & & & & & & & $22(20)$ & NT & NT & 21 & 16 \\
\hline
\end{tabular}

${ }^{a} \mathrm{Mn}$, acid produced from mannitol; $\mathrm{R}$, acid produced from raffinose; $\mathrm{M}$, acid produced from melibiose; 1 , acid produced from lactose; Hyl, production of hyaluronidase; L, Lancefield group antigen; $\mathrm{H}$, hemolysis; Mt, motility on chocolate agar; $\beta \mathrm{g}$, $\beta$-D-galactosidase activity.

${ }^{b} \beta$, beta-hemolysis.

Level of DNA relatedness obtained under relaxed conditions $\left(60^{\circ} \mathrm{C}\right)$. The values in parentheses are the DNA relatedness values obtained under stringent conditions $\left(75^{\circ} \mathrm{C}\right.$ ).

${ }^{d}$ NT, not tested.

${ }^{e} \mathrm{~N}$, nongroupable. 
$\mathrm{kDa}$

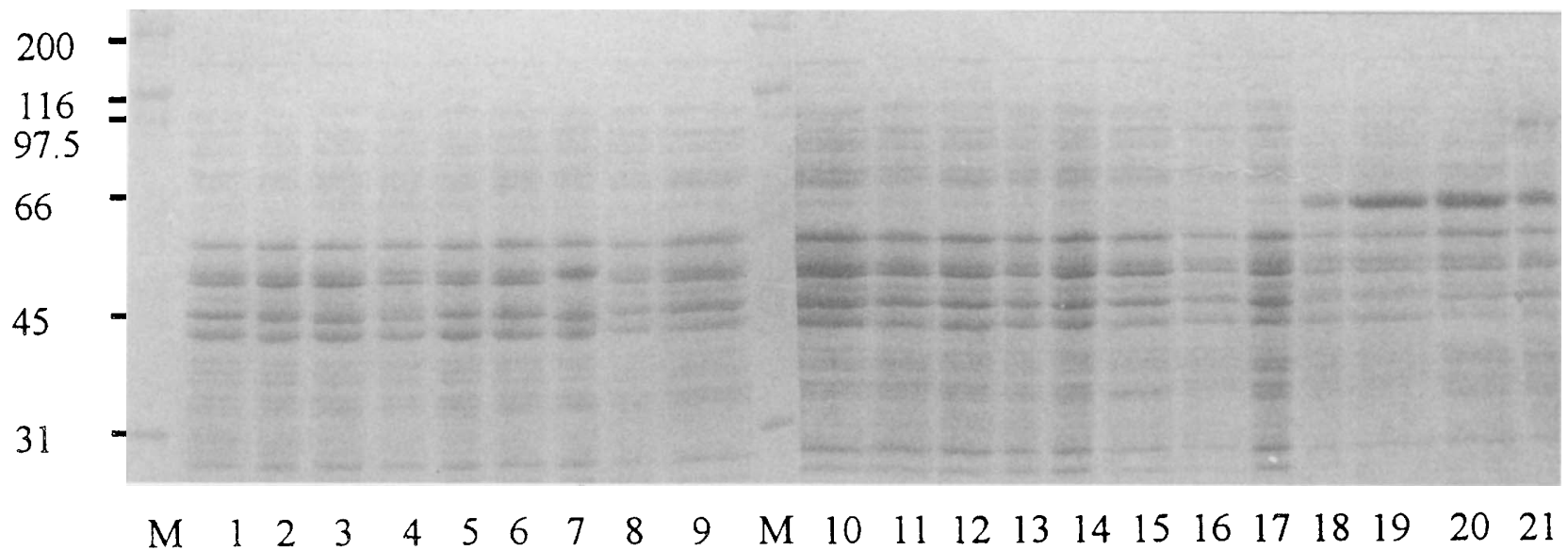

FIG. 1. Whole-cell polypeptide patterns of $S$. anginosus strains. Lanes M, molecular weight markers, including myosin (molecular weight, 200,000), $\beta$-galactosidase (116,000), phosphorylase B $(97,500)$, bovine serum albumin $(66,000)$, ovalbumin $(45,000)$, and carbonic anhydrase $(31,000)$; lane 1, NCTC $10713^{\mathrm{T}}$; lane 2 , 1007-77; lane 3, SL28; lane 4, G5:3; lane 5, ATCC 9895; lane 6, PC4890; lane 7, PHLS 430; lane 8, 153ii; lane 9, KR455; lane 10, 138ii; lane 11, Q3799; lane 12, Q4039; lane 13, KR687; lane 14, 757; lane 15, SJMC; lane 16, MGH; lane 17, 69130; lane 18, W558; lane 19, NMH3; lane 20, I751s; lane 21, M5823.

tively heavy band at a molecular weight of approximately 63,000 but otherwise produced the same overall band pattern as the rest of the strains.

16S-23S rRNA intergenic spacer size polymorphisms. Examples of the size polymorphisms observed in the PCR products corresponding to the $16 \mathrm{~S}-23 \mathrm{~S}$ intergenic spacer regions of $S$. anginosus are shown in Fig. 2. A single PCR product was obtained in all cases. The majority of the strains that did not ferment mannitol gave a 450 -bp PCR product (strains NCTC $10713^{\mathbf{T}}, 1007-77$, SL28, G5:3, ATCC 9895, PC4890, and PHLS 430), while mannitol-fermenting strains 153ii, 138ii, KR455, KR687, Q3799, Q4039, 757, SJMC, and 69130) gave a 350-bp product. The exceptions were strain $\mathrm{MGH}$, a motile strain that did not ferment mannitol, which gave a 350-bp PCR product, and the four beta-hemolytic Lancefield group C strains (strains

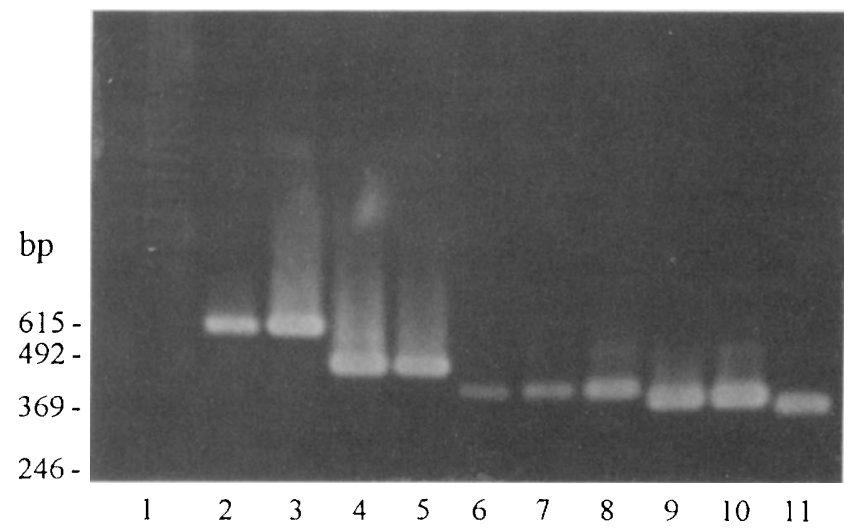

FIG. 2. 16S-23S ribosomal DNA spacer PCR products. Lane 1, 123-bp ladder; lanes 2 and 3, 600-bp product ( $S$. anginosus beta-hemolytic Lanceficld group $\mathrm{C}$ hyaluronidase-producing strains W558 and NMH3, respectively); lanes 4 and 5,450 -bp product ( $S$. anginosus mannitol-nonfermenting strains NCTC $10713^{\mathrm{T}}$ and SL28, respectively); lanes 6 and 7, 380-bp product (S. anginosus beta-hemolytic Lancefield group $C$ hyaluronidase-nonproducing strains 1751 s and M5823, respectively); lane 8,380-bp product (S. constellatus NCDO 2226 ${ }^{\mathrm{T}}$ ); lanes 9 and 10,350 -bp product ( $S$. anginosus mannitol-fermenting strains $153 \mathrm{ii}$ and Q3799, respectively); lane 11, 327-bp product (S. intermedius $\mathrm{NCDO} 2227^{\mathrm{T}}$ ).
I751s and M5823 gave a 380-bp product, while strains W558 and NMH3 gave a 600-bp PCR product).

Ribotyping. The ribotyping results are shown in Fig. 3. As determined by visual assessment, the majority of the strains fell into two main ribotype groups, and intragroup pattern variation was observed. The first of the two groups, designated

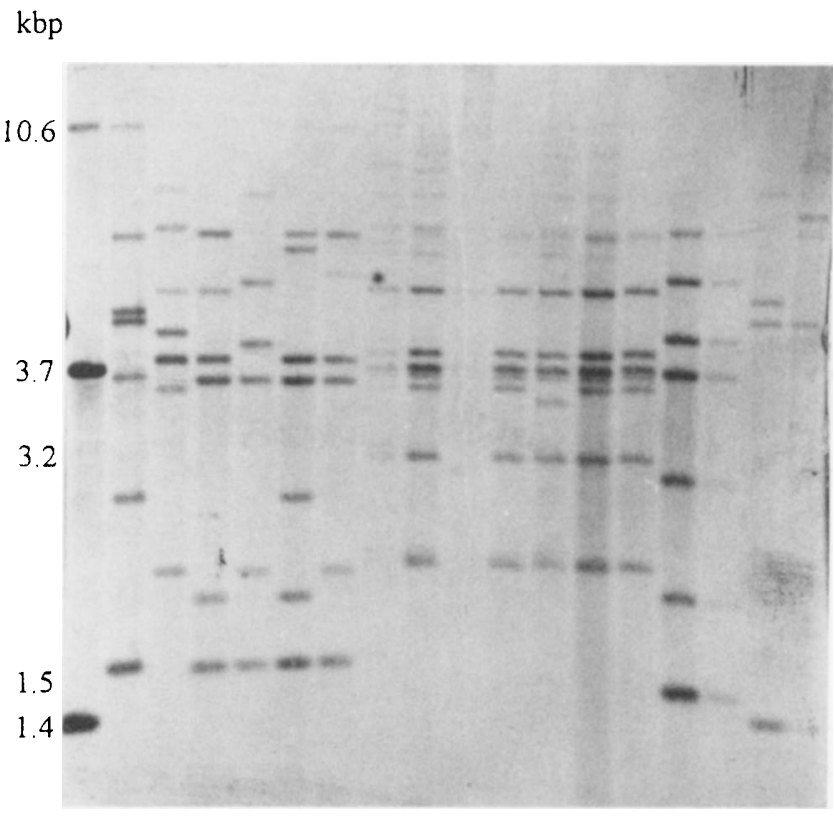

$1 \quad 2 \quad 3 \quad 4 \quad 5 \quad 6 \quad 7 \quad 8 \quad 9 \quad 10111212131415 \quad 16 \quad 1718$

FIG. 3. Ribotype patterns of $S$. anginosus strains as determined with HindIII-digested DNA. Lane $1, S$. constellatus NCDO $2226^{\mathrm{T}}$; lane $2, S$. interme dius NCDO $2227^{\mathrm{T}}$; lanes 3 through 7, S. anginosus ribogroup 1 strains NCTC $10713^{\mathbf{T}}, \mathrm{G} 5: 3,1007-77$, PHLS 430, and SL28, respectively; lanes 8 through $14, S$ anginosus ribogroup 2 strains O3799, SJMC, 757, 153ii, $138 \mathrm{ii}, \mathrm{MGH}$, and 69130 respectively; lanes 15 through $18, S$. anginosus beta-hemolytic Lancefield group C strains NMH3 and W558 (hyaluronidase producing) and strains M5823 and 1751s (hyaluronidase nonproducing), respectively. 
ribogroup 1, comprised strains G5:3, 1007-77, PHLS 430, and SL28, which did not ferment mannitol, and type strain NCTC 10713. The second group, designated ribogroup 2, included mannitol-fermenting strains Q3799, 757, 153ii, and 138ii together with mannitol-fermenting motile strains SJMC and 69130. Strain MGH (a motile strain which did not ferment mannitol) also produced a pattern typical of ribogroup 2 . The ribogroup 1 patterns were characterized by the presence of a $1.5-\mathrm{kbp}$ fragment in all of the patterns except the NCTC $10713^{\mathrm{T}}$ pattern and by the absence of a $3.2-\mathrm{kbp}$ fragment that was present in all of the ribogroup 2 patterns. In addition, the ribogroup 2 patterns differed from the ribogroup 1 patterns by the presence of four closely migrating fragments at approximately 3.6 to $4.3 \mathrm{kbp}$. Two of the four beta-hemolytic Lancefield group C strains, NMH3 and W558, produced identical ribotype patterns, whereas the ribotype patterns of strains M5823 and 1751s were both unique. None of the beta-hemolytic Lancefield group $\mathrm{C}$ strains produced ribotype patterns that could be readily included in ribogroups 1 or 2 , although there was a close resemblance between the patterns obtained for strains NMH3 and W558 and the patterns obtained for the ribogroup 1 strains.

DNA reassociation. The levels of DNA reassociation obtained under relaxed $\left(60^{\circ} \mathrm{C}\right)$ and stringent $\left(75^{\circ} \mathrm{C}\right)$ conditions are shown in Table 2. The levels of DNA homology obtained under relaxed conditions showed that the majority of the $S$. anginosus strains were closely related (but occasionally values of $<60 \%$ were recorded) when labelled DNAs from strains NCTC $10713^{\mathrm{T}}$, 138ii, and 69130 were used. The exceptions to this were beta-hemolytic Lancefield group C strains I751s and M5823 (both of which are hyaluronidase negative), which together formed a separate homology group, even under stringent conditions, and strains ATCC 9895 and 1007-77, which gave low homology values in all experiments. The remaining beta-hemolytic Lancefield group C strains, strains NMH3 and W558 (both of which are hyaluronidase positive), also exhibited a closer relationship to each other than to any other strain, although these strains also exhibited higher levels of relatedness to the main group of strains formed in the experiments when labelled DNAs from NCTC $10713^{\mathrm{T}}$, 138ii, and 69130 were used than I751s and M5823 exhibited. For the most part the homology levels obtained with type strain NCTC 10713 under stringent conditions were considerably lower (in most cases less than $60 \%$ ); the only two exceptions to this were the levels of homology to strains KR455 and SJMC. The results obtained when labelled DNAs from mannitol-fermenting strain 138ii and mannitol-fermenting motile strain 69130 were used indicate that strains with these phenotypes exhibit higher levels of homology than strains that do not ferment mannitol, although no clear-cut division was observed between the two phenotypes.

\section{DISCUSSION}

The results of this study demonstrate that $S$. anginosus, as currently defined, is heterogeneous at both the species level and the intraspecies (subspecies) level. Strains I751s and M5823 formed a separate DNA homology group under both relaxed and stringent hybridization conditions. The levels of DNA homology observed indicate that these organisms form a distinct species that may be more closely related to other $S$. anginosus strains, including type strain NCTC 10713, than to either $S$. intermedius or $S$. constellatus, although the low levels of DNA homology between I751s and a few S. anginosus strains obtained under stringent hybridization conditions indicate that further work, including $16 \mathrm{~S}$ rDNA sequencing, will be required in order to clarify the latter relationship. The unusual phenotype of strains I751s and M5823 (beta-hemolysis, Lancefield group $\mathrm{C}$, production of $\beta$-D-galactosidase and hyaluronidase, mannitol not fermented), together with the 16S-23S rRNA intergenic spacer polymorphism data, ribotyping data, and whole-cell polypeptide patterns determined by SDSPAGE, support the idea that these members of the anginosus group represent an as-yet-undescribed species. In the study of Winstanley et al. (32), beta-hemolytic Lancefield group C streptococci belonging to the SMG also formed a separate cluster as determined by pyrolysis mass spectrometry. The previously undetermined role of the beta-hemolytic Lancefield group $\mathrm{C}$ strains belonging to the SMG in human pharyngitis $(12,19,23)$ and the observations that these organisms are able to bind large amounts of albumin from humans and other animals and to aggregate rat platelets $(30,31)$ make these strains a particularly interesting area for further study. However, the recent finding of Ahmet et al. (1), that a high proportion of $S$. anginosus strains scored positive for detectable $\beta$-D-galactosidase activity after hypercapnic incubation indicates that it may be desirable to identify additional differential biochemical tests for use with these strains and to ensure that standardized conditions for testing are adhered to.

The results obtained in the DNA base pairing experiments show that strains ATCC 9895 and 1007-77 represent other undescribed taxa within the anginosus group. Previous studies that have included strain ATCC 9895 have also revealed low levels of DNA homology between this organism and other recognized taxa belonging to the SMG $(18,29)$. The results of DNA hybridization experiments carried out in this study with labelled DNAs from strains with different phenotypes also did not place ATCC 9895 or 1007-77 in any particular group of strains. Further work will be required to reveal the taxonomic positions of these streptococci.

With the exception of the strains discussed above, the strains which we examined, including the type strain, form a closely related group within which some genotypic and phenotypic heterogeneity is observed. Although in some cases DNA homology levels of less than $60 \%$ were obtained, particularly under stringent hybridization conditions, no clear-cut subdivision of these strains is possible. However, the following conclusions were reached regarding the intraspecific structure of $S$. anginosus. Beta-hemolytic Lancefield group C hyaluronidase-producing strains NMH3 and W558, in contrast to strains I751s and M5823, do not form a separate homology group at the species level but do exhibit a relatively close relationship with each other (levels of DNA homology, 87 to $100 \%$ ) compared with other members of the species and can also be differentiated from other strains on the basis of ribotype, on the basis of 16S-23S rRNA intergenic spacer size, and on the basis of SDS-PAGE polypeptide pattern. Therefore, these strains may constitute a subspecies of $S$. anginosus. The production of a heavy $63-\mathrm{kDa}$ band on SDS-PAGE gels by both beta-hemolytic Lancefield group $C$ strains that produce hyaluronidase and beta-hemolytic Lancefield group $\mathrm{C}$ strains that do not produce hyaluronidase and the placement of these organisms in separate DNA homology groups demonstrate that production of the $63-\mathrm{kDa}$ band is not a species-specific phenotypic characteristic. Despite differences between strains that ferment mannitol and strains that do not ferment mannitol in 16S-23S rRNA intergenic spacer sizes and in ribotypes, we found no convincing evidence in our DNA homology studies that these two groups of strains constitute separate species or clear-cut subspecies. The data also show that the motile strains described previously by Bergman et al. (3) and regarded by these authors as possible representatives of a new species do 
in fact belong in $S$. anginosus. Interestingly, the levels of DNA homology between $S$. anginosus type strain NCTC 10713 and all other strains were lower than the level of DNA homology obtained for the homologous control, particularly under stringent hybridization conditions. While the relationship between NCTC $10713^{\mathrm{T}}$ and other $S$. anginosus strains is obviously very close, these data, combined with the relatively unusual phenotype of this strain (fermentation of raffinose and mannitol, beta-hemolysis, Lancefield group $\mathrm{G}$ ) and its ribotype (Fig. 3), suggest that NCTC $10713^{\mathrm{T}}$ may not, in fact, be the best strain to represent this species as it is currently defined.

While the data obtained in this study for beta-hemolytic Lancefield group C strains, as well as strains ATCC 9895 and 1007-77, demonstrate that $S$. anginosus is a heterogeneous species that requires further division at the species level and possibly at the subspecies level, we believe that any formal taxonomic proposals must wait until sufficient numbers of strains belonging to the DNA homology groups have been examined and a differential biochemical scheme for identification has been established. In a recent study of " $S$. milleri" performed by Jacobs et al. (15), who used a $16 \mathrm{~S}$ rRNA gene fragment as a species-specific probe, virtually all of the strains (199 of 200 strains) phenotypically identified as $S$. anginosus reacted with the probe for this species. However, one strain reacted with the $S$. constellatus probe, and two strains identified as $S$. intermedius reacted with the $S$. anginosus probe. The strains that gave these reactions should be included in future studies of the SMG. Clearly, the probes used for identifying these streptococci, like the probes used for any other group of bacteria, will have to be reviewed as taxonomic changes occur. In addition, no formal proposals concerning the suitability of NCTC 10713 as the type strain of this species are being made here, although this strain is clearly not the most typical representative of $S$. anginosus.

\section{REFERENCES}

1. Ahmet, Z., M. Warren, and E. T. Houang. 1995. Species identification of members of the Streptococcus milleri group isolated from the vagina by ID 32 Strep System and differential phenotypic testing. J. Clin. Microbiol. 33:15921595 .

2. Bentley, R. W., J. A. Leigh, and M. D. Collins. 1991. Intrageneric structure of Streptococcus based on comparative analysis of small-subunit rRNA sequences. Int. J. Syst. Bacteriol. 41:487-494.

3. Bergman, S., M. Selig, M. D. Collins, J. A. E. Farrow, E. J. Baron, G. R. Dickersin, and K. L. Ruoff. 1995. "Streptococcus milleri" strains displaying a gliding type of motility. Int. J. Syst. Bacteriol. 45:235-239.

4. Brosius, J., M. A. Raker, A. Gray, T. J. Dull, R. R. Gutell, and H. F. Noller. 1981. Construction and fine mapping of recombinant plasmids containing the rrnB ribosomal RNA operon of E. coli. Plasmid 6:112-118.

5. Cookson, B., H. Talsania, S. Chinn, and I. Phillips. 1989. A qualitative and quantitative study of the cellular fatty acids of 'Streptococcus milleri' with capillary gas chromatography. J. Gen. Microbiol. 135:831-838.

6. Coykendall, A. L., P. M. Wesbecher, and K. B. Gustafson. 1987. "Streptococcus milleri," Streptococcus constellatus, and Streptococcus intermedius are later synonyms of Streptococcus anginosus. Int. J. Syst. Bacteriol. 37:222-228.

7. Crosa, J. H., D. J. Brenner, and S. Falkow. 1973. Use of a single-strand nuclease for analysis of bacterial and plasmid deoxyribonucleic acid homoand heteroduplexes. J. Bacteriol. 115:904-911.

8. Doit, C., F. Grimont, R. A. Whiley, B. Regnault, P. A. D. Grimont, J. M. Hardie, and A. Bouvet. 1994. Ribotypes of the "Streptococcus milleri-group" allow discrimination between strains of Streptococcus constellatus, Streptococcus intermedius and Streptococcus anginosus, p. 531-532. In A. Totolian (ed.), Pathogenic streptococci present and future. Lancer Publication, St. Petersburg, Russia.

9. Ezaki, T., R. Facklam, N. Takeuchi, and E. Yabuuchi. 1986. Genetic relatedness between the type strain of Streptococcus anginosus and minute-colony-forming beta-hemolytic streptococci carrying different Lancefield grouping antigens. Int. J. Syst. Bacteriol. 36:345-347.
10. Facklam, R. R. 1984. The major differences in the American and British Streptococcus taxonomy schemes with special reference to Streptococcus milleri. Eur. J. Clin. Microbiol. 3:91-93.

11. Farrow, J. A. E., and M. D. Collins. 1984. Taxonomic studies on streptococci of serological groups $\mathrm{C}, \mathrm{G}$ and $\mathrm{L}$ and possibly related taxa. Syst. Appl. Microbiol. 5:483-493.

12. Fox, K., J. Turner, and A. Fox. 1993. Role of beta-hemolytic streptococci in pharyngitis: incidence and biochemical characteristics of Streptococcus equisimilis and Streptococcus anginosus in patients and healthy controls. J. Clin. Microbiol. 31:804-807.

13. Garvie, E. I. 1976. Hybridization between the deoxyribonucleic acid of some strains of hetero-fermentative lactic acid bacteria. Int. J. Syst. Bacteriol. 26:116-122.

14. Gossling, J. 1988. Occurrence and pathogenicity of the Streptococcus miller group. Rev. Infect. Dis. 10:257-285.

15. Jacobs, J. A., C. S. Schot, A. E. Bunschoten, and L. M. Schouls. 1996. Rapid identification of "Streptococcus milleri" strains by line blot hybridization identification of a distinct $16 \mathrm{~S}$ rRNA population closely related to Streptococcus constellatus. J. Clin. Microbiol. 34:1717-1721.

16. Kawamura, Y., X.-G. Hou, F. Sultana, H. Miura, and T. Ezaki. 1995. Determination of 16S rRNA sequences of Streptococcus mitis and Streptococcus gordonii and phylogenetic relationships among members of the genus Streptococcus. Int. J. Syst. Bacteriol. 45:406-408.

17. Kilpper-Bälz, R., B. L. Williams, R. Luttiken, and K. H. Schleifer. 1984 Relatedness of 'Streptococcus milleri' with Streptococcus anginosus and Streptococcus constellatus. Syst. Appl. Microbiol. 5:494-500.

18. Knight, R. G., and D. M. Shlaes. 1988. Physiological characteristics and deoxyribonucleic acid relatedness of Streptococcus intermedius strains. Int. J. Syst. Bacteriol. 38:19-24.

19. Lawrence, J., D. M. Yuko, and W. K. Hadley. 1985. Incidence and charac terization of beta-hemolytic Streptococcus milleri and differentiation from $S$. pyogenes (group A), S. equisimilis (group C), and large-colony group G streptococci. J. Clin. Microbiol. 22:772-777.

20. Piscitelli, S. C., J. Shrwed, P. Schreckenberger, and L. H. Danziger. 1992 Streptococcus milleri group: renewed interest in an elusive pathogen. Eur. J. Clin. Microbiol. Infect. Dis, 11:491-498.

21. Shah, H. N., T. J. M. Van Steenbergen, J. M. Hardie, and J. De Graaff. 1982 DNA base composition, DNA-DNA reassociation and isoelectrofocussing of proteins of strains designated Bacteroides oralis. FEMS Microbiol. Lett. 13: $125-130$.

22. Smith, R. F., and N. P. Willet. 1968. Rapid plate method for screening hyaluronidase- and chondroitin sulfatase-producing microorganisms. Appl. Microbiol. 16:1434-1436.

23. Vance, D. W. 1992. Group C streptococci: 'Streptococcus equisimilis' or Streptococcus anginosus? Clin. Infect. Dis. 14:616.

24. Welborn, P. R., W. K. Hadley, E. Newborn, and D. M. Yajko. 1983. Characterization of strains of viridans streptococci by deoxyribonucleic acid hybridization and physiological tests. Int. J. Syst. Bacteriol. 33:293-299.

25. Whiley, R. A., and D. Beighton. 1991. Emended descriptions and recognition of Streptococcus constellatus, Streptococcus intermedius, and Streptococcus anginosus as distinct species. Int. J. Syst. Bacteriol. 41:1-5.

26. Whiley, R. A., D. Beighton, T. G. Winstanley, H. Y. Fraser, and J. M. Hardie. 1992. Streptococcus intermedius, Streptococcus constellatus, and Streptococcus anginosus (the Streptococcus milleri group): association with different body sites and clinical infections. J. Clin. Microbiol. 30:243-244.

27. Whiley, R. A., B. Duke, J. M. Hardie, and L. M. C. Hall. 1995. Heterogeneity among 16S-23S rRNA intragenic spacers of species within the 'Streptococcus milleri group.' Microbiology 141:1461-1467.

28. Whiley, R. A., H. Fraser, J. M. Hardie, and D. Beighton. 1990. Phenotypic differentiation of Streptococcus intermedius, Streptococcus constellatus, and Streptococcus anginosus strains within the "Streptococcus milleri group." J. Clin. Microbiol. 28:1497-1501.

29. Whiley, R. A., and J. M. Hardie. 1989. DNA-DNA hybridisation studies and phenotypic characterisation of strains within the 'Streptococcus milleri group.' J. Gen. Microbiol. 135:2623-2633.

30. Willcox, M. D. P. 1995. Potential pathogenic properties of members of the 'Streptococcus milleri' group in relation to the production of endocarditis and abscesses. J. Med. Microbiol. 43:405-410.

31. Willcox, M. D. P., M. Patrikakis, C. Y. Loo, and K. W. Knox. 1993. Albuminbinding proteins on the surface of the Streptococcus milleri group and characterization of the albumin receptor of Streptococcus intermedius C5. J. Gen Microbiol. 139:2451-2458.

32. Winstanley, T. G., J. T. Magee, D. I. Limb, J. M. Hindmarch, R. C. Spencer, R. A. Whiley, D. Beighton, and J. M. Hardie. 1992. A numerical taxonomic study of the 'Streptococcus milleri' group based upon conventional phenotypic tests and pyrolysis mass spectrometry. J. Med. Microbiol. 36:149-155. 